\title{
Field-Oriented Control based on Hysteresis Band Current Controller for a Permanent Magnet Synchronous Motor driven by a Direct Matrix Converter
}

\author{
Jianwei Zhang ${ }^{1 *}$, Haitao Yang ${ }^{1}$, Tianshi Wang ${ }^{1}, \mathrm{Li} \mathrm{Li}^{1}$, David G. Dorrell ${ }^{2}$, Dylan Dah-Chuan Lu ${ }^{1}$ \\ ${ }^{1}$ Faculty of Engineering and IT, University of Technology Sydney, Sydney, Australia \\ ${ }^{2}$ Howard College Campus, University of KwaZulu-Natal, Durban, South Africa \\ *Jianwei.Zhang@uts.edu.au
}

\begin{abstract}
The hysteresis band controller offers excellent dynamic performance. It has been widely researched and applied for the voltage source inverter and inverter fed drives, however it has not been investigated within the context of a matrix converter or a matrix converter based motor drive. In this paper, both fixed-band and sinusoidal-band hysteresis current controllers are proposed and developed for a direct matrix converter. A comprehensive comparative evaluation of the two methods is then carried out. Both methods have fast dynamic performance and they inherently integrate the line modulation technique of the virtual rectifier stage into the overall modulation. Surge currents are prevented with the proposed scheme. The sinusoidal-band hysteresis controller demonstrates lower total harmonic distortion at the expense of higher average switching frequency, which is only significantly observable at very high sampling frequencies. The proposed controller is integrated with the field-oriented control to drive a matrix converter fed permanent magnet synchronous machine. The proposed methods are simple and incur a light computational burden, which advances the practical applications of matrix converters in AC motor drives. The simulation and experiment results demonstrate the effectiveness and feasibility of the proposed scheme.
\end{abstract}

\section{Introduction}

Field-oriented control (FOC) is a classical control approach for electrical machines and it is the most commonly employed linear control strategy for medium- and low-power motor drives [1]. Nowadays, FOC-based electrical drive systems are mature and utilized extensively in highperformance drives [2]. Current controllers are vital components in the FOC method. Meanwhile, electrical drive systems composed of an induction motor (IM) and a voltage source inverter (VSI) are prevalent in adjustable speed drives in industry [3]. For the VSI based drive system, current controllers are preferred for the high-performance drives because of their excellent dynamic behaviour. Among these current controllers, the hysteresis band (HB) current controller features inherent current limiting capability, robustness, no modulation stage, and simple implementation, in addition to the excellent dynamic and tracking performance [4]. The HB controller has been mainly used in the VSI, and active research on this includes constant switching frequency control [5], online computation of bands [6], and multi-band hysteresis control [7][8]. In [9], a comparative study of fixed-band and sinusoidal-band hysteresis current controllers (F-HB and S-HB) was carried out for VSIs; however, hysteresis bands are impractical and the comparison needs further evaluation for various band widths and sampling frequencies. In the literature, there is no detailed published research on either F-HB or S-HB control for a direct matrix converter (MC) [10].

In VSI-fed motor drive systems, a dynamic braking chopper is usually required to absorb the kinetic energy generated during motor deceleration or from a generator operational mode unless back-to-back converters are used. These will make the system bulkier, decrease the efficiency and increase the complexity.
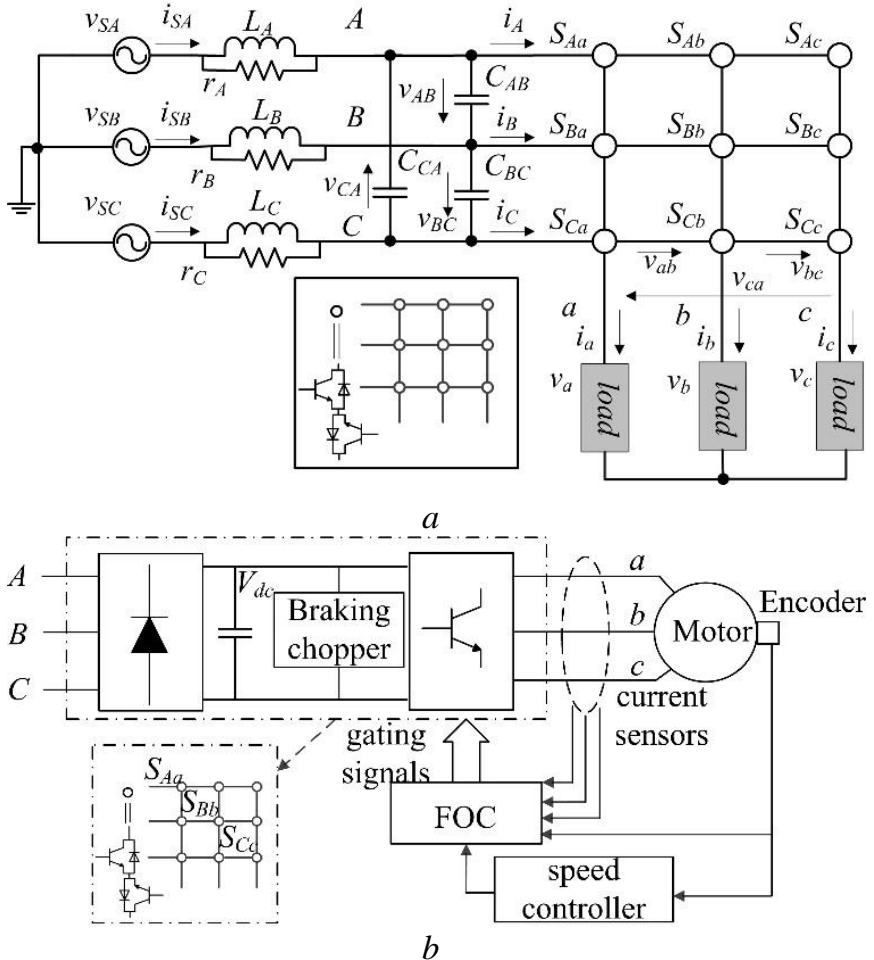

Fig. 1. (a) A direct $3 \times 3$ MC structure with filters, (b) the FOC controlled drive system with VSI or MC.

These problems can be addressed with the MC based drive system using F-HB and S-HB control techniques. A $3 \times 3$ direct MC, as shown in Fig. 1(a), is a flexible power converter which is capable of bidirectional power flow, sinusoidal waveform, regenerative ability, controllable input power factor and compact volume [11]-[13]. With an MC-based drive system, one significant benefit is that the braking chopper is removed as shown in Fig. 1(b). Therefore fourquadrant operation is enabled. In addition to motor drive 
applications, the MC and its derivatives have been proposed for numerous applications including aerospace systems [14], microgrids [15], FACTS [16] and electric vehicles [17].

In terms of MC fed motor drives, most research is focused on the induction machine [18]-[20] while only few are concerned with the permanent magnet synchronous machine (PMSM) [21]. PMSMs are more efficient compared with the induction motor since they do not have rotor current and this reduces the overall losses; and PMSMs have permanent excitation so no excitation current is required. Other merits of the PMSM include high torque-to-current ratio, low inertia and compact design. Because of these, the PMSM is gaining increasing interest and popularity in highperformance variable-speed drives. In an MC-based PMSM drive system, the favourable features of the MC and PMSM can be combined for a high-performance drive application.

For the control of MC-based drives, many methods have been proposed. Direct torque control (DTC) and predictive torque control (PTC) have been researched for the MC-based drive systems [18]-[24]. With regards to DTC control, the known issues of high torque ripple especially in low-speed operation, persist. In the case of predictive control, the computing burden is heavy because of the high number of switch actions (27 possibilities) of the MC. Another standard control strategy is the space vector modulation (SVM) based proportional-integral (PI) controller. This controller requires an SVM modulation stage and has more demands in terms of parameters tuning. This is because of an extra current PI controller is introduced, in addition to the common speed PI controller. This controller also requires two synchronous reference frame transformations $(a b c \leftrightarrow d q)$. In contrast, the proposed control requires only one PI controller and one frame transformation. In fact, the FOC based method is rarely investigated for MC based motor drives. $\mathrm{HB}$ and $\mathrm{HB}$-based FOC for a $3 \times 3$ direct $\mathrm{MC}$ in an MC-based drive remain unexplored even though the $\mathrm{HB}$ controller is simple and has a low computational burden.

This work proposes and studies the HB current controller and HB based FOC for an MC fed PMSM drive. Several features of the MC and PMSM can be integrated into one system. Compared with space vector modulation (SVM) based control strategies [25], the proposed controller does not require an extra modulation stage but includes the modulation of the virtual rectifier stage of the MC. The proposed HB controller requires only one synchronous frame transformation $(d q \rightarrow a b c)$ when used in an MC fed motor drive. This reduces the complexity and reduces the computational burden. Both F-HB and S-HB current controllers are developed and compared. Both methods demonstrate good dynamic features. Comparative results show that the S-HB controller has less low-order harmonics and lower total harmonic distortion (THD) at the cost of the higher average switching frequency. However, according to the comparative studies, the better performance of the S-HB in terms of THD is only appreciably observable when the sampling interval is very short. Furthermore, HB current controllers are integrated with the FOC to drive a PMSM with an MC. S-HB shows slightly lower stator currents and torque ripple. The braking chopper is not required in this structure. The proposed method is very simple, effective and practical to implement; this is an advancement with respect to industrial applications of the MC-based drive system.

\section{HB controller for the MC output currents}

\subsection{Basics}

As shown in Fig. 1(a), a three-phase direct MC consists of nine bidirectional semiconductor switches. The arrangement of these switches forms a $3 \times 3$ switch matrix expressed by

$$
\begin{gathered}
{\left[\begin{array}{c}
v_{a} \\
v_{b} \\
v_{c}
\end{array}\right]=\left[\begin{array}{lll}
S_{A a} & S_{B a} & S_{C a} \\
S_{A b} & S_{B b} & S_{C b} \\
S_{A c} & S_{B c} & S_{C c}
\end{array}\right]\left[\begin{array}{l}
v_{A} \\
v_{B} \\
v_{C}
\end{array}\right]=S\left[\begin{array}{l}
v_{A} \\
v_{B} \\
v_{C}
\end{array}\right]} \\
{\left[\begin{array}{l}
i_{A} \\
i_{B} \\
i_{C}
\end{array}\right]=\left[\begin{array}{lll}
S_{A a} & S_{A b} & S_{A c} \\
S_{B a} & S_{B b} & S_{B c} \\
S_{C a} & S_{C b} & S_{C c}
\end{array}\right]\left[\begin{array}{l}
i_{a} \\
i_{b} \\
i_{c}
\end{array}\right]=S^{T}\left[\begin{array}{l}
i_{a} \\
i_{b} \\
i_{c}
\end{array}\right]} \\
\sum_{X=A, B, C} S_{X x}=1,(x=a, b, c)
\end{gathered}
$$

where $S$ (transpose $S^{T}$ ) is the switch matrix which controls the MC output voltages and input currents. The elements $S_{X x}$ in the switch matrix can be assigned either a value of one (for the on state) or zero (for the off state). $v_{A, B, C}, i_{A, B, C}, v_{a, b, c}$ and $i_{a, b, c}$ are the input and output phase voltages and currents respectively (denoted in Fig. 1(a)).

The constraints (3) are applied to exclude switch states that short-circuit the inputs (usually voltage sources) and that open-circuit the outputs (usually inductive loads). With any control strategies, this constraint should be complied with. Otherwise, overcurrent and overvoltage will be generated which can damage devices. Therefore, there are 27 switch states allowable in the matrix which represent 27 control actions (finite control set).

\subsection{Fixed-Band Hysteresis Control for MC}

The rationale of $\mathrm{HB}$ controller is simple. The HB current controller for the VSI is illustrated in Fig. 2(a) for one of the phases and described by

$$
\begin{aligned}
& i_{\text {upper }}=I_{\text {ref }} \sin \left(\omega_{\text {ref }} t+\theta_{\text {ref }}\right)+\frac{h}{2} \\
& i_{\text {lower }}=I_{\text {ref }} \sin \left(\omega_{\text {ref }} t+\theta_{\text {ref }}\right)-\frac{h}{2} \\
& \text { If } i_{a}>i_{\text {upper }}, v_{a o}=-0.5 V_{d c} \\
& \text { if } i_{a}<i_{\text {lower }}, v_{a o}=+0.5 V_{d c}
\end{aligned}
$$

where $I_{\text {ref }}$ is the amplitude of the reference current and $h$ is the hysteresis controller band width and it is fixed (F-HB, Fig. $2(\mathrm{c}))$. $\theta_{\text {ref }}$ and $\omega_{\text {ref }}$ are the initial phase angle and angular frequency of the phase $a$ reference current. $i_{\text {upper }}$ and $i_{\text {lower }}$ are the upper and lower bands of the HB current controller. $i_{a}$ is the actual current of phase $a$. $V_{d c}$ is the DC link voltage and $v_{a o}$ is the applied voltage across output phase $a$ and the neutral point of DC link. The control law (5) is straightforward. When the actual current exceeds the upper band, the upper/lower leg is turned off/on to reduce the current and vice versa. Therefore, the actual currents will always be regulated to stay within the prescribed boundaries in theory. Similarly the HB current controllers for an MC can be developed. 
In terms of the MC, the upper and lower bands in (4) for the F-HB are shown in Fig. 2(b). The controller law is obtained in a manner similar to VSI with modifications. In Fig. 2(b) single phase current control is depicted and the maximum or minimum voltage is selected to increase or decrease the currents where:

$$
\begin{aligned}
& \text { If } i_{a}>i_{\text {upper }}, v_{a}=\operatorname{minimum}\left(v_{A}, v_{B}, v_{C}\right) \\
& \text { if } i_{a}<i_{\text {lower }}, v_{a}=\operatorname{maximum}\left(v_{A}, v_{B}, v_{C}\right)
\end{aligned}
$$

general, there are three levels of voltages available in MC rather than two in VSI. This flexibility benefits the implementation of multi-band HB control [26].

\subsection{Sinusoidal-Band Hysteresis Control for MC}

The sinusoidal bands are shown in Fig. 2(d) and can be expressed as

It is worth noting that the MC offers more flexibility compared with VSI as it offers more voltage choices. In
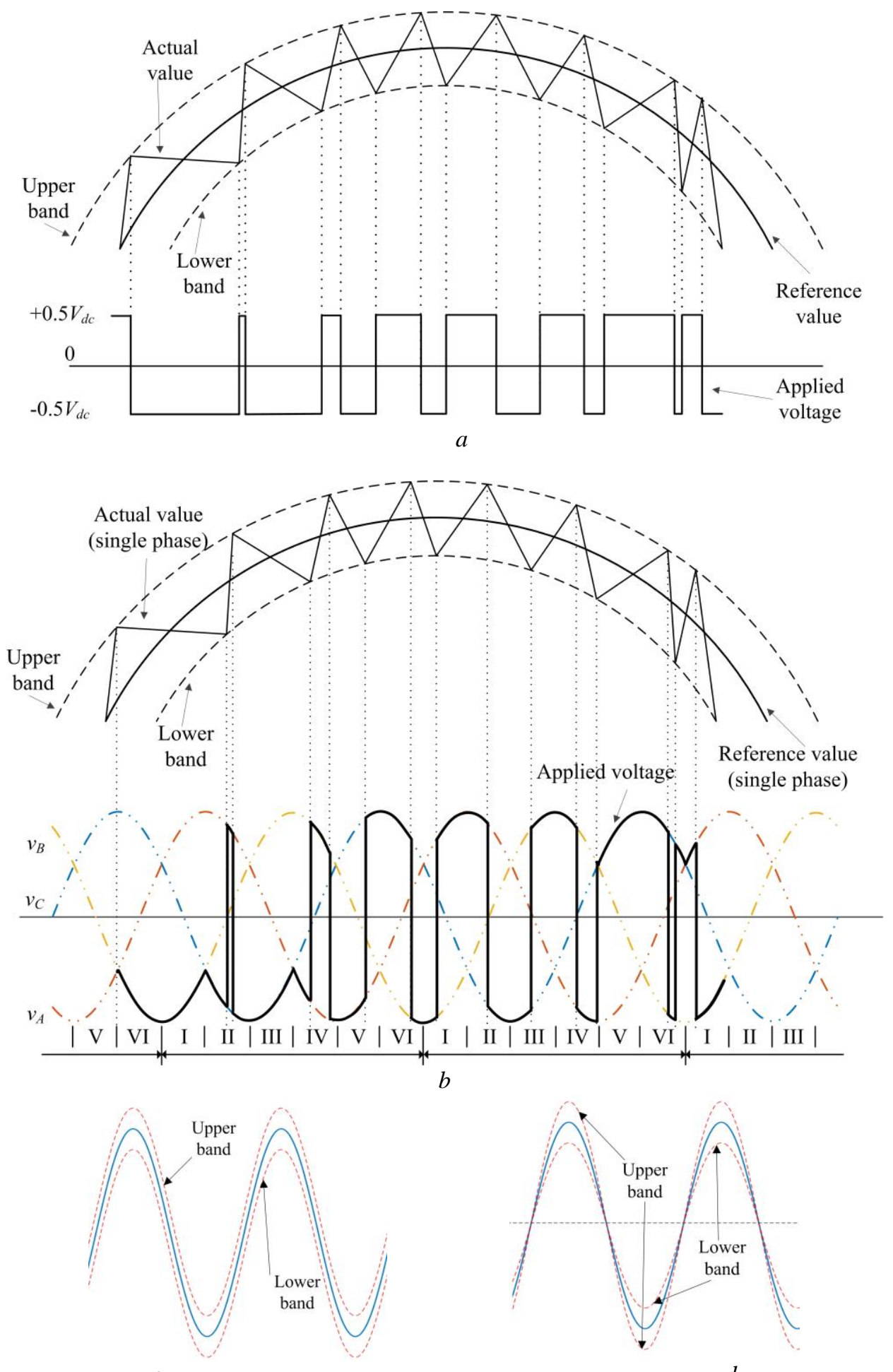

$d$

Fig. 2. HB current controller diagrams: (a) HB for the VSI, (b) HB for the MC, (c) F-HB band, (d) S-HB band. 
Table 1 Switch states look-up table of F-HB control for MC.

\begin{tabular}{|c|c|c|c|c|c|c|}
\hline & I & II & III & IV & $\mathrm{V}$ & VI \\
\hline 001 & $\mathrm{~S}_{\mathrm{Aa}}, \mathrm{S}_{\mathrm{Ab}}, \mathrm{S}_{\mathrm{Bc}}$ & $\mathrm{S}_{\mathrm{Aa}}, \mathrm{S}_{\mathrm{Ab}}, \mathrm{S}_{\mathrm{Cc}}$ & $\mathrm{S}_{\mathrm{Ba}}, \mathrm{S}_{\mathrm{Bb}}, \mathrm{S}_{\mathrm{Cc}}$ & $\mathrm{S}_{\mathrm{Ba}}, \mathrm{S}_{\mathrm{Bb}}, \mathrm{S}_{\mathrm{Ac}}$ & $\mathrm{S}_{\mathrm{Ca}}, \mathrm{S}_{\mathrm{Cb}}, \mathrm{S}_{\mathrm{Ac}}$ & $\mathrm{S}_{\mathrm{Ca}}, \mathrm{S}_{\mathrm{Cb}}, \mathrm{S}_{\mathrm{Bc}}$ \\
\hline 010 & $\mathrm{~S}_{\mathrm{Aa}}, \mathrm{S}_{\mathrm{Bb}}, \mathrm{S}_{\mathrm{Ac}}$ & $\mathrm{S}_{\mathrm{Aa}}, \mathrm{S}_{\mathrm{Cb}}, \mathrm{S}_{\mathrm{Ac}}$ & $\mathrm{S}_{\mathrm{Ba}}, \mathrm{S}_{\mathrm{Cb}}, \mathrm{S}_{\mathrm{Bc}}$ & $\mathrm{S}_{\mathrm{Ba}}, \mathrm{S}_{\mathrm{Ab}}, \mathrm{S}_{\mathrm{Bc}}$ & $\mathrm{S}_{\mathrm{Ca}}, \mathrm{S}_{\mathrm{Ab}}, \mathrm{S}_{\mathrm{Cc}}$ & $\mathrm{S}_{\mathrm{Ca}}, \mathrm{S}_{\mathrm{Bb}}, \mathrm{S}_{\mathrm{Cc}}$ \\
\hline 011 & $\mathrm{~S}_{\mathrm{Aa}}, \mathrm{S}_{\mathrm{Bb}}, \mathrm{S}_{\mathrm{Bc}}$ & $\mathrm{S}_{\mathrm{Aa}}, \mathrm{S}_{\mathrm{Cb}}, \mathrm{S}_{\mathrm{Cc}}$ & $\mathrm{S}_{\mathrm{Ba}}, \mathrm{S}_{\mathrm{Cb}}, \mathrm{S}_{\mathrm{Cc}}$ & $\mathrm{S}_{\mathrm{Ba}}, \mathrm{S}_{\mathrm{Ab}}, \mathrm{S}_{\mathrm{Ac}}$ & $\mathrm{S}_{\mathrm{Ca}}, \mathrm{S}_{\mathrm{Ab}}, \mathrm{S}_{\mathrm{Ac}}$ & $\mathrm{S}_{\mathrm{Ca}}, \mathrm{S}_{\mathrm{Bb}}, \mathrm{S}_{\mathrm{Bc}}$ \\
\hline 100 & $\mathrm{~S}_{\mathrm{Ba}}, \mathrm{S}_{\mathrm{Ab}}, \mathrm{S}_{\mathrm{Ac}}$ & $\mathrm{S}_{\mathrm{Ca}}, \mathrm{S}_{\mathrm{Ab}}, \mathrm{S}_{\mathrm{Ac}}$ & $\mathrm{S}_{\mathrm{Ca}}, \mathrm{S}_{\mathrm{Bb}}, \mathrm{S}_{\mathrm{Bc}}$ & $\mathrm{S}_{\mathrm{Aa}}, \mathrm{S}_{\mathrm{Bb}}, \mathrm{S}_{\mathrm{Bc}}$ & $\mathrm{S}_{\mathrm{Aa}}, \mathrm{S}_{\mathrm{Cb}}, \mathrm{S}_{\mathrm{Cc}}$ & $\mathrm{S}_{\mathrm{Ba}}, \mathrm{S}_{\mathrm{Cb}}, \mathrm{S}_{\mathrm{Cc}}$ \\
\hline 101 & $\mathrm{~S}_{\mathrm{Ba}}, \mathrm{S}_{\mathrm{Ab}}, \mathrm{S}_{\mathrm{Bc}}$ & $\mathrm{S}_{\mathrm{Ca}}, \mathrm{S}_{\mathrm{Ab}}, \mathrm{S}_{\mathrm{Cc}}$ & $\mathrm{S}_{\mathrm{Ca}}, \mathrm{S}_{\mathrm{Bb}}, \mathrm{S}_{\mathrm{Cc}}$ & $\mathrm{S}_{\mathrm{Aa}}, \mathrm{S}_{\mathrm{Bb}}, \mathrm{S}_{\mathrm{Ac}}$ & $\mathrm{S}_{\mathrm{Aa}}, \mathrm{S}_{\mathrm{Cb}}, \mathrm{S}_{\mathrm{Ac}}$ & $\mathrm{S}_{\mathrm{Ba}}, \mathrm{S}_{\mathrm{Cb}}, \mathrm{S}_{\mathrm{Bc}}$ \\
\hline 110 & $\mathrm{~S}_{\mathrm{Ba}}, \mathrm{S}_{\mathrm{Bb}}, \mathrm{S}_{\mathrm{Ac}}$ & $\mathrm{S}_{\mathrm{Ca}}, \mathrm{S}_{\mathrm{Cb}}, \mathrm{S}_{\mathrm{Ac}}$ & $\mathrm{S}_{\mathrm{Ca}}, \mathrm{S}_{\mathrm{Cb}}, \mathrm{S}_{\mathrm{Bc}}$ & $\mathrm{S}_{\mathrm{Aa}}, \mathrm{S}_{\mathrm{Ab}}, \mathrm{S}_{\mathrm{Bc}}$ & $\mathrm{S}_{\mathrm{Aa}}, \mathrm{S}_{\mathrm{Ab}}, \mathrm{S}_{\mathrm{Cc}}$ & $\mathrm{S}_{\mathrm{Ba}}, \mathrm{S}_{\mathrm{Bb}}, \mathrm{S}_{\mathrm{Cc}}$ \\
\hline
\end{tabular}

$$
\begin{aligned}
& i_{\text {upper }}=\left(\mathrm{I}_{\text {ref }}+\frac{h}{2}\right) \sin \left(\omega_{\text {ref }} t+\theta_{\text {ref }}\right) \\
& i_{\text {lower }}=\left(\mathrm{I}_{\text {ref }}-\frac{h}{2}\right) \sin \left(\omega_{\text {ref }} t+\theta_{\text {ref }}\right)
\end{aligned}
$$

With S-HB, the control law is slightly modified as the relative locations of upper and lower bands are alternated every half cycle, for $a$-phase:

$$
\begin{array}{r}
\text { For } i_{\text {ref }}>0, \text { if } i_{a}>i_{\text {upper }}, v_{a}=\operatorname{minimum}\left(v_{A}, v_{B}, v_{C}\right) \\
\text { if } i_{a}<i_{\text {lower }}, v_{a}=\operatorname{maximum}\left(v_{A}, v_{B}, v_{C}\right) \\
\text { For } i_{\text {ref }}<0, \text { if } i_{a}>i_{\text {upper }}, v_{a}=\operatorname{maximum}\left(v_{A}, v_{B}, v_{C}\right) \\
\text { if } i_{a}<i_{\text {lower }}, v_{a}=\operatorname{minimum}\left(v_{A}, v_{B}, v_{C}\right)
\end{array}
$$

where $i_{\text {ref }}=I_{\text {ref }} \sin \left(\omega_{\text {ref }} t+\theta_{\text {ref }}\right)$ is the reference current. If the reference current is in the positive half cycle and when the actual current exceeds the upper band, the voltage which enables current reduction is selected; when the actual current reaches the lower band, the voltage which drives current increase is selected; see (8). Alternatively, if the reference current is in the negative half cycle and when the actual current exceeds the upper band, the maximum voltage which is able to increase the current is employed; when the actual current reaches the lower band, the minimum voltage which can decrease the current is used; see (9). Therefore, the actual currents can be theoretically controlled to be within the region with the predefined band-width. The above methods are demonstrated for a single-phase case and it can be readily extended to the three-phase case because of symmetry.

\section{Overall modulation of MC}

A switching look-up table for the F-HB can be derived and this is shown in Table 1. It is based on the hysteresis controller and input voltage sectors (Fig. 2(b)). The F-HB hysteresis comparator outputs, which are used as indices in the look-up Table 1, are described by

$$
\left\{\begin{array}{l}
H B_{x}=0, \text { if } I_{x}<I_{x-\text { lower }} \\
H B_{x}=1, \text { if } I_{x}>I_{x-\text { upper }}
\end{array} x=a, b, c\right.
$$

The output values in (10) correspond to the digits of the first column in Table 1. For example, the index 001 indicates $i_{a}<i_{\text {a-lower }}, i_{b}<i_{\text {b-lower }}$ and $i_{c}>i_{c \text {-upper }}$. The input voltage sectors, which show the amplitude relationships of the input voltages, are used to determine the switch states. For instance, if the input voltages are in Sector I, switches $S_{A a}, S_{A b}$ and $S_{B c}$ are turned on since $v_{A}$ is maximum and $v_{B}$ is minimum; see Fig. 2(b). Therefore, $i_{a}$ and $i_{b}$ will increase while $i_{c}$ will decrease. A switching look-up table can also be obtained for the S-HB controller in a very similar manner, therefore it is not shown here to avoid redundancy. There are
$18 \mathrm{MC}$ switch states in Table 1; they correspond to 18 active $\mathrm{MC}$ vectors.

The above methods integrate the line-commutated modulation of the MC input currents. To explain this, the overall MC modulation is divided into a virtual rectifier and a virtual inverter stage as shown in Fig. 3(a). These two virtual stages can be modulated independently using different methods. The output current of the virtual inverter stage is modulated with the VSI HB control, while the input current of the virtual rectifier stage is regulated with a linecommutated approach. For example, in F-HB, if the output phase $a$ current $i_{\mathrm{a}}$ reaches the lower band $\left(i_{\mathrm{a}}<i_{a-l o w e r}\right)$ and the maximum input voltage is $v_{B}$ at this moment, then $S_{P a}$ and $S_{P B}$ in Fig. 3(a) are turned on in order to increase the current $i_{a}$. Turning on the switches $S_{P a}$ and $S_{P B}$ results in the connection between the output phase $a$ and input phase $B$. Therefore, the equivalent switch $S_{B a}$ in Fig. 1(a) is switched on. The same rule applies to other situations. As a consequence, the input currents are controlled automatically. An equivalent look-up table can be tabulated based on this. It is worth noting that different modulation techniques, such as SVM, for the virtual
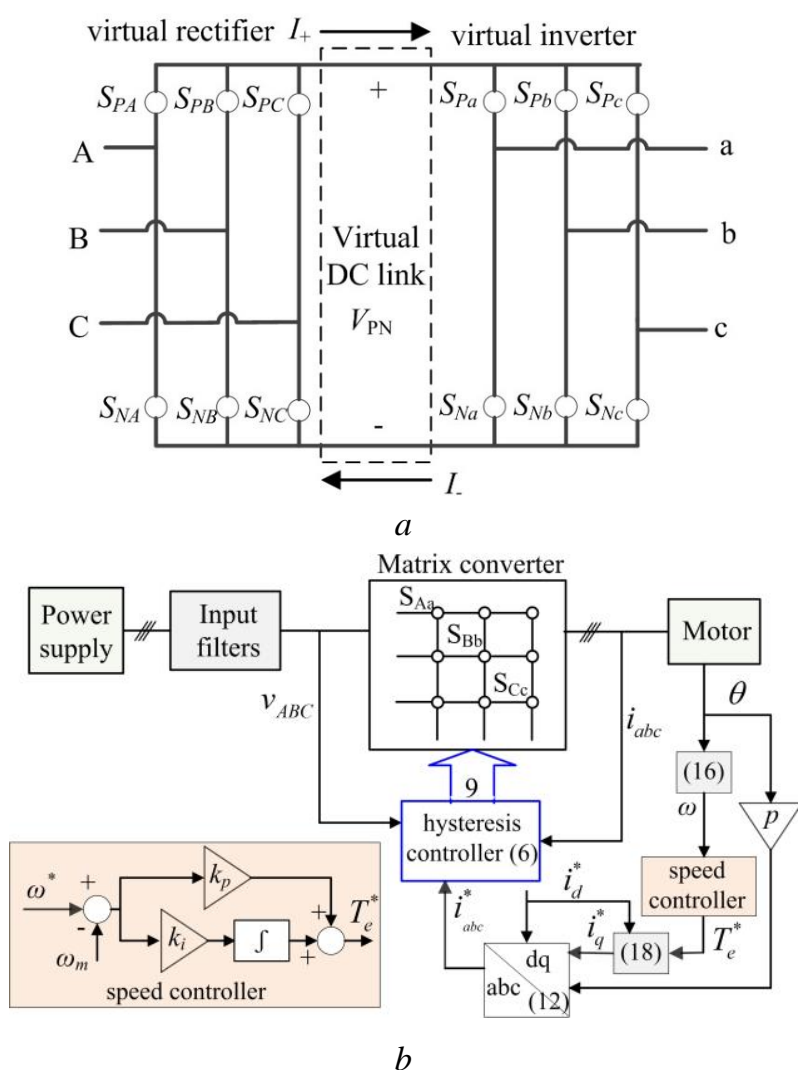

Fig. 3. (a) The equivalent virtual rectifier and inverter stage for the overall modulation explanation, (b) $\mathrm{HB}$ FOC controller diagram for MC based PMSM drive. 
rectifier stage, can be incorporated into the overall modulation scheme to control the input currents.

\section{FOC with $\mathrm{HB}$ controller for PMSM}

\subsection{PMSM Model Description}

In this section, FOC is implemented for the MC based PMSM drive system using the HB current controller. The FOC converts the AC motor dynamics so they are similar to an equivalent DC motor where the torque and flux are decoupled. FOC relies upon the fact that the motor rotor flux and torque can be controlled through the $\mathrm{d}$ and $\mathrm{q}$ components of the stator current which are usually provided by a currentcontrolled PWM inverter. This is achieved by using the $a b c$ to $d q$ fame transformation,

$$
\left[\begin{array}{l}
i_{d} \\
i_{q} \\
i_{0}
\end{array}\right]=\left[\begin{array}{ccc}
\cos \left(\theta_{s}\right) & \cos \left(\theta_{s}-\frac{2 \pi}{3}\right) & \cos \left(\theta_{s}+\frac{2 \pi}{3}\right) \\
-\sin \left(\theta_{s}\right) & -\sin \left(\theta_{s}-\frac{2 \pi}{3}\right) & -\sin \left(\theta_{s}+\frac{2 \pi}{3}\right) \\
0.5 & 0.5 & 0.5
\end{array}\right]\left[\begin{array}{c}
i_{a} \\
i_{b} \\
i_{c}
\end{array}\right]
$$

and the reverse transformation,

$$
\left[\begin{array}{l}
i_{a} \\
i_{b} \\
i_{c}
\end{array}\right]=\left[\begin{array}{ccc}
\cos \left(\theta_{s}\right) & -\sin \left(\theta_{s}\right) & 1 \\
\cos \left(\theta_{s}-\frac{2 \pi}{3}\right) & -\sin \left(\theta_{s}-\frac{2 \pi}{3}\right) & 1 \\
\cos \left(\theta_{s}+\frac{2 \pi}{3}\right) & -\sin \left(\theta_{s}+\frac{2 \pi}{3}\right) & 1
\end{array}\right]\left[\begin{array}{l}
i_{d} \\
i_{q} \\
i_{0}
\end{array}\right]
$$

where $i_{a, b, c}$ are the three phase currents in the $a b c$ system and $i_{d, q, 0}$ are the currents in $d q$ system. $i_{0}=0$ for a balanced threephase system. $\theta_{s}$ is the synchronous reference angle which can be obtained from an encoder.

Using synchronous reference frame transformations, the PMSM model equations can be obtained for the FOC control [27] and they can be expressed as

$$
\begin{aligned}
& \frac{d i_{d}}{d t}=\frac{v_{d}}{L_{d}}-\frac{R_{s}}{L_{d}} i_{d}+\frac{L_{q}}{L_{d}} p \omega_{m} i_{q} \\
& \frac{d i_{q}}{d t}=\frac{v_{q}}{L_{q}}-\frac{R_{s}}{L_{q}} i_{q}-\frac{L_{d}}{L_{q}} p \omega_{m} i_{d}-\frac{\psi_{f} p \omega_{m}}{L_{q}} \\
& \psi_{d}=L_{d} i_{d}+\psi_{f} \quad \psi_{q}=L_{q} i_{q} \\
& \qquad \frac{d \theta}{d t}=\omega_{m} \\
& T_{e}=\frac{3}{2} p\left[\psi_{f} i_{q}+\left(L_{d}-L_{q}\right) i_{d} i_{q}\right]
\end{aligned}
$$

where $L_{d}$ and $L_{q}$ are PMSM d- and q-axis inductance; $p$ is the number of pole pairs; $R_{S}$ is the stator resistance; $\psi_{f}$ is the flux established by permanent magnet; $\psi_{d}$ and $\psi_{q}$ are stator flux components in $\mathrm{d}$ and $\mathrm{q}$ axis; $v_{d}$ and $v_{q}$ are the stator voltage components in the $d q$ axis; $\theta$ is the rotor angular position, and $\omega_{m}$ is the rotor speed. $T_{e}$ is the electromagnetic motor torque. $\omega^{*}$ in the figures is the rotor speed reference. In the tested surface-mounted PMSM, $L_{d}=L_{q}$ because the permanent magnets are surface mounted and the inductance in every position is same, which simplifies (17) to

$$
T_{e}=\frac{3}{2} p \psi_{f} i_{q} \Rightarrow i_{q}=\frac{2}{3 p \psi_{f}} T_{e}
$$

If $i_{d}=0$ holds, the maximum torque per ampere control can be achieved for the tested non-salient pole PMSM. The electromagnetic torque generated by a PMSM can be controlled by the q-axis component of the stator current. In order to carry out the coordinate transformation $(d q \rightarrow a b c)$ in (12), the rotor position is obtained from an encoder. The torque reference $T_{e}{ }^{*}$ can be either specified by the operator or obtained from a closed-loop speed controller. Here a PI controller is used to generate the torque reference from the rotor speed error. The obtained $i_{q}{ }^{*}$ reference together with $i_{d}{ }^{*}$

\begin{tabular}{|c|c|c|c|c|c|c|c|c|c|c|c|c|c|}
\hline \multicolumn{2}{|c|}{$T_{s}(\mu \mathrm{s})$} & \multicolumn{3}{|c|}{10} & \multicolumn{3}{|c|}{30} & \multicolumn{3}{|c|}{50} & \multicolumn{3}{|c|}{100} \\
\hline \multicolumn{2}{|c|}{$h(\mathrm{~A})$} & 0.02 & 0.05 & 0.1 & 0.02 & 0.05 & 0.1 & 0.02 & 0.05 & 0.1 & 0.02 & 0.05 & 0.1 \\
\hline \multirow{2}{*}{ THD (\%) } & F-HB & 0.73 & 1.19 & 1.83 & 1.91 & 2.00 & 3.01 & 3.37 & 3.06 & 3.54 & 6.80 & 6.64 & 6.42 \\
\hline & S-HB & 0.68 & 0.74 & 1.08 & 2.05 & 2.02 & 2.08 & 3.38 & 3.36 & 3.35 & 6.84 & 6.98 & 6.87 \\
\hline \multirow{2}{*}{$\begin{array}{c}\text { Average } \\
\text { switching } \\
\text { frequency } \\
(\mathrm{kHz})\end{array}$} & F-HB & 9.85 & 6.95 & 4.52 & 3.93 & 3.54 & 2.75 & 2.43 & 2.33 & 2.03 & 1.25 & 1.21 & 1.17 \\
\hline & S-HB & 10.4 & 8.9 & 8.75 & 3.95 & 3.59 & 3.17 & 2.44 & 2.33 & 2.11 & 1.23 & 1.22 & 1.19 \\
\hline
\end{tabular}
are converted into $i^{*}{ }_{a b c}$ in the $a b c$ frame and then sent to the MC HB controller.

Table 2 Matrix converter input power supply, filter and load parameters.

\begin{tabular}{ccccccc}
\hline$V_{S A}(\mathrm{~V})$ & $f_{s}(\mathrm{~Hz})$ & $L_{A}(\mathrm{mH})$ & $r_{A}(\Omega)$ & $C_{A B}(\mu \mathrm{F})$ & $R_{L}(\Omega)$ & $L_{L}(\mathrm{mH})$ \\
\hline 40 & 50 & 4.8 & 30 & 15 & 5 & 10 \\
\hline
\end{tabular}

Table 3 PMSM system and controller parameters for F-HB based MC-PMSM drive.

\begin{tabular}{cccccccccccc}
\hline$R_{s}(\Omega)$ & $L_{d}(\mathrm{mH})$ & $L_{q}(\mathrm{mH})$ & $p$ & $J\left(\mathrm{~kg} \cdot \mathrm{m}^{2}\right)$ & $\varphi_{f}(\mathrm{~Wb})$ & $\omega_{N}(\mathrm{rpm})$ & $T_{N}(\mathrm{~N} \cdot \mathrm{m})$ & $k_{p}$ & $k_{i}$ & $h$ & $T_{s}(\mathrm{~s})$ \\
\hline 1.8 & 14.2 & 15.9 & 3 & 0.002 & 0.1057 & 1500 & 4.5 & 0.05 & 1 & 0.02 & $50 \times 10^{-6}$ \\
\hline
\end{tabular}

Table 4 Comparative results for performances of F-HB and S-HB. 
If $i_{d}=0$ holds, the maximum torque per ampere control can be achieved for the tested non-salient pole PMSM. The electromagnetic torque generated by a PMSM can be controlled by the q-axis component of the stator current. In order to carry out the coordinate transformation $(d q \rightarrow a b c)$ in (12), the rotor position is obtained from an encoder. The torque reference $T_{e}{ }^{*}$ can be either specified by the operator or obtained from a closed-loop speed controller. Here a PI controller is used to generate the torque reference from the rotor speed error. The obtained $i_{q}{ }^{*}$ reference together with $i_{d}{ }^{*}$ are converted into $i_{a b c}^{*}$ in the $a b c$ frame and then sent to the MC HB controller.

\subsection{HB-FOC Controller Design}

Based on the model derived above, the FOC controller combined with the $\mathrm{HB}$ controller can be designed for the MC based PMSM drive as shown in Fig. 3(b). The HB controller generates gating signals for the semiconductor devices and sensors are used to measure the motor speed and currents. The speed controller adopted in this work is a common PI controller whose parameters are given in Table 3.

\section{Simulation and experimental results}

\subsection{Simulation Results}

The simulated system and controller parameters, unless elsewhere specified, are tabulated in Tables 2 and 3. The loads under test are three-phase inductive loads. The steady-state simulation results of F-HB and S-HB tracking reference currents $i_{a b c-r e f}=[3 \sin (120 \pi t) 3 \sin (120 \pi t-2 \pi / 3)$ $3 \sin (120 \pi t+2 \pi / 3)]$ A under various sampling intervals and HB bands are tabulated in Table 4. As summarized in this table, S-HB exhibits better THD performance, while average switching frequencies are higher though. These are only appreciably observable when sampling interval is sufficiently short.
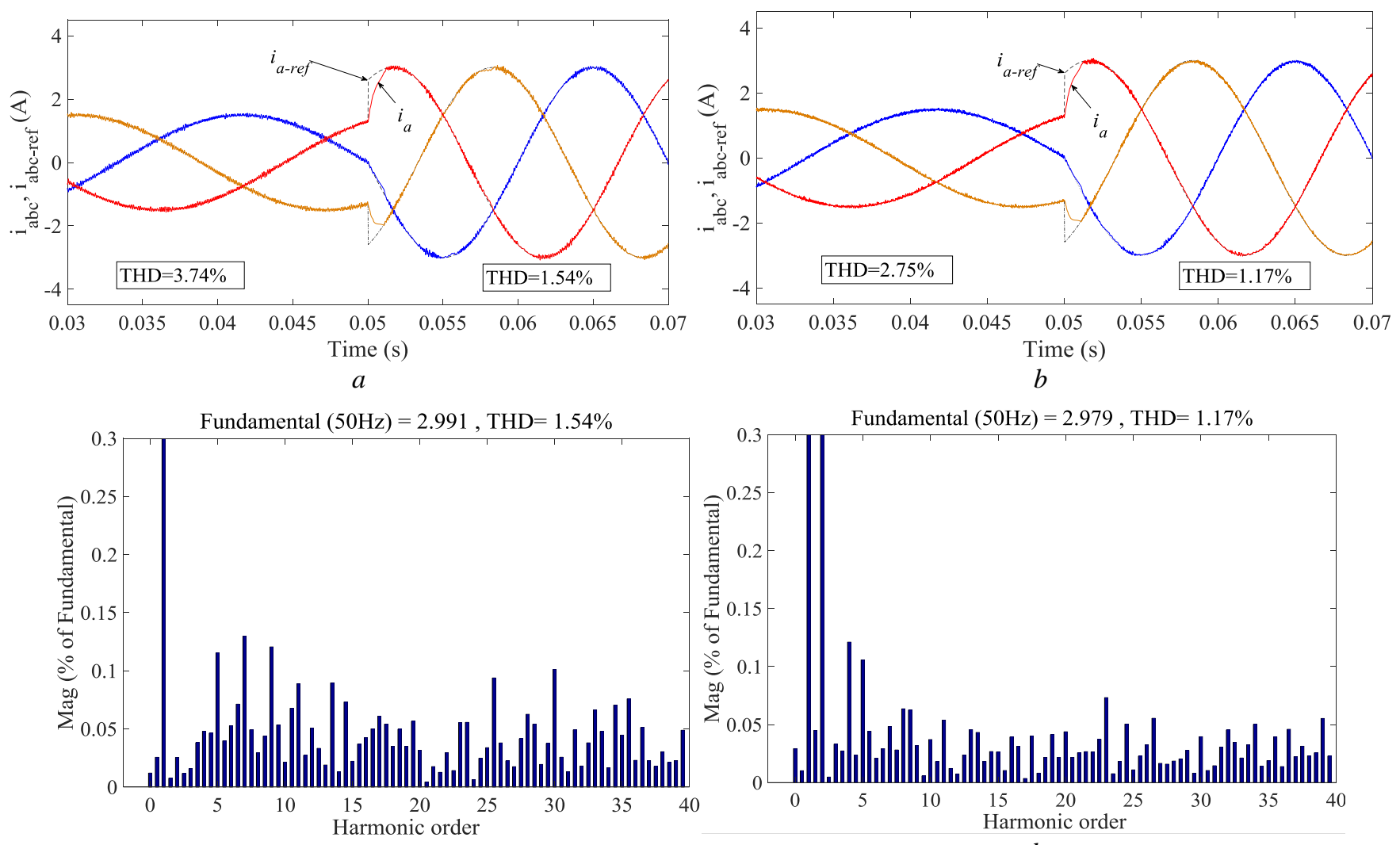

$c$
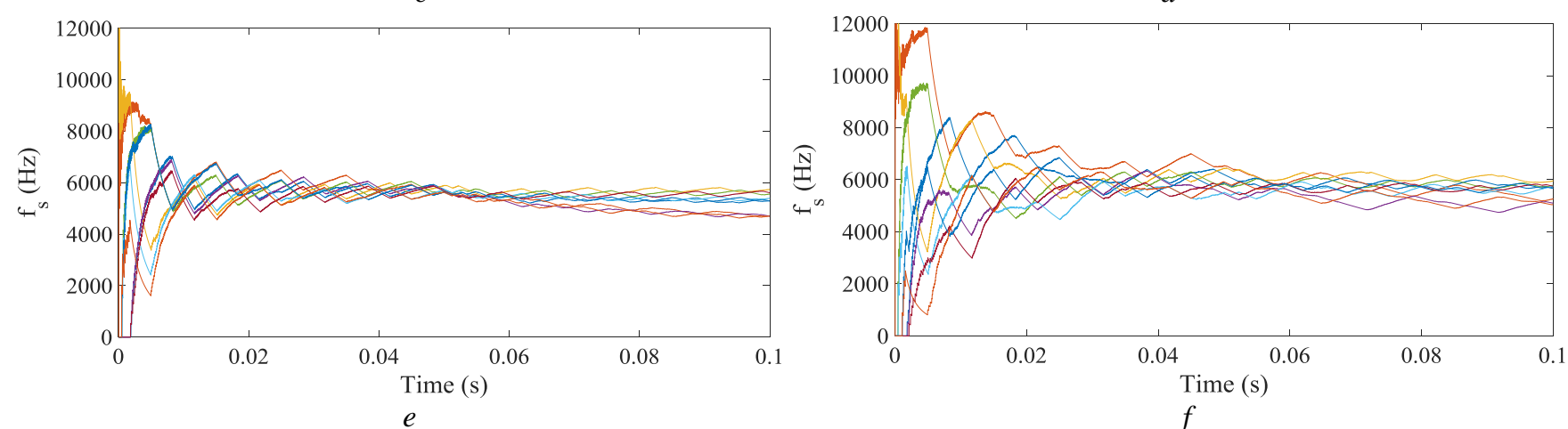

Fig. 4. Simulation results of HB current controller for $M C$ : (a) F-HB controller currents dynamic performance, (b) S-HB controller currents dynamic performance, (c) F-HB output current FFT analysis, (d) S-HB output current FFT analysis, (e) F$H B$ average switching frequency, $(\boldsymbol{f}) S$-HB average switching frequency. 
The dynamic responses of the F-HB and S-HB controllers are shown and compared in Fig. 4. Here $h=0.05$ $\mathrm{A}$ and $T_{s}=20 \mu \mathrm{s}$. The current references are $i_{a b c}{ }^{*}=$ [1.5sin $(60 \pi t) 1.5 \sin (60 \pi t-2 \pi / 3) 1.5 \sin (60 \pi t+2 \pi / 3)]$ A before $0.025 \mathrm{~s}$ and $[3 \sin (100 \pi t) 3 \sin (100 \pi t-2 \pi / 3) 3 \sin (100 \pi t+2 \pi / 3)]$ after $0.025 \mathrm{~s}$. According to the simulation results shown in Fig. 4(a) and (b), it is convincing to say that both methods present excellent dynamic performance in regulation currents. Compared with F-HB, the THD values are reduced from $3.74 \%$ and $1.54 \%$ to $2.75 \%$ and $1.17 \%$ respectively in the S-HB while the average switching frequencies are relatively higher. This can be observed in Fig. 4(c) to (f). From the fast Fourier transform (FFT) analysis, in Fig. 4(c) and (d), for the second part of the current, it can be seen that harmonics are reduced in a wide range whereas the secondorder harmonic is increased. The average switching frequencies (shown in Fig. 4(e) and (f)) and consequential switching losses are not very high. The superior performance of S-HB is observable only when the sampling interval is small (high frequency). Therefore, for the practical implementation, it is not worth considering S-HB.

The simulation work of the proposed control strategy for the MC based PMSM drive was carried out and simulation results are presented in Fig. 5. The parameters of the rotor speed PI controller are $k_{p}=0.5$ and $k_{i}=0.55$. Transient behaviour of the PMSM stator currents, rotor speed and electromagnetic torque are shown under a speed change from 500 to $-300 \mathrm{rpm}$ when the load torque $T_{L}=1.5 \mathrm{~N} \cdot \mathrm{m}$. As observed from the figure, the proposed control strategy shows good regulation performance. F-HB and S-HB methods have very similar performances. S-HB has a slightly lower current THD $(5.85 \%)$ than F-HB $(5.99 \%)$. The torque ripples of the $\mathrm{S}-\mathrm{HB}$ range from 1.336 to $1.626 \mathrm{~N} \cdot \mathrm{m}$ while the torque ripples
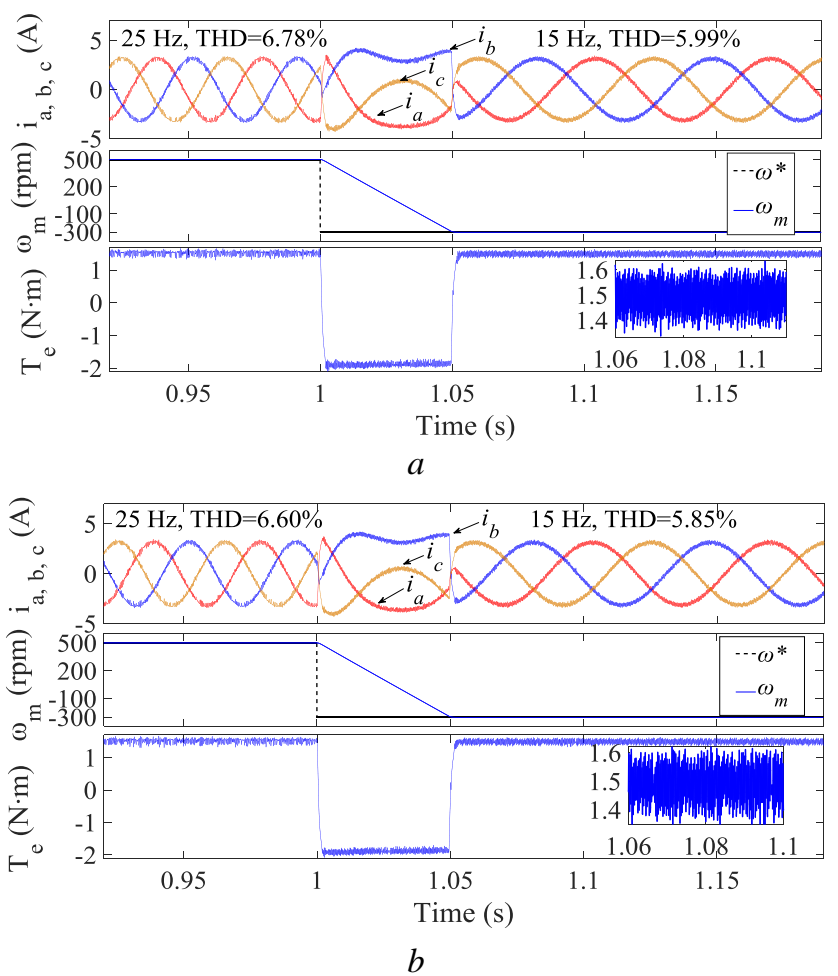

Fig. 5. Simulation results of HB-FOC for MC based PMSM drive system in response to the speed change from +500 to $300 \mathrm{rpm}$ at $1 \mathrm{~s}$ when $T_{L}=1.5 \mathrm{~N} \cdot \mathrm{m}$.

(a) F-HB, (b) $S-H B$. of the F-HB range from 1.333 to $1.639 \mathrm{~N} \cdot \mathrm{m}$. These demonstrate slightly better performance for S-HB.

\subsection{Experimental Verification}

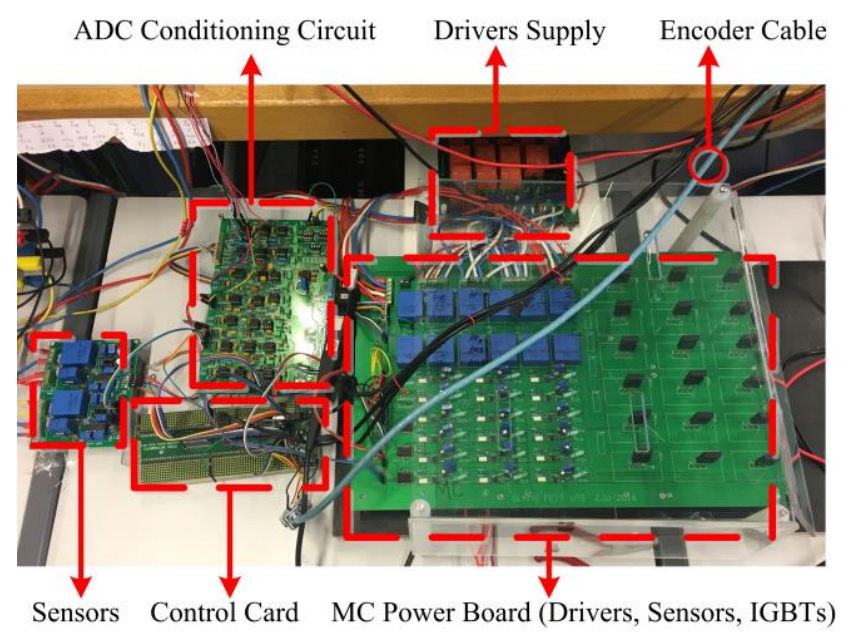

Sensors Control Card MC Power Board (Drivers, Sensors, IGBTs) a

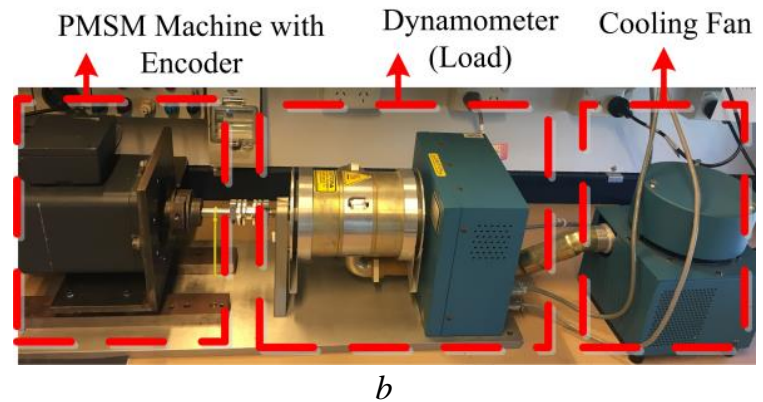

Fig. 6. The experimental set up: (a) MC hardware board, (b) PMSM test bench.

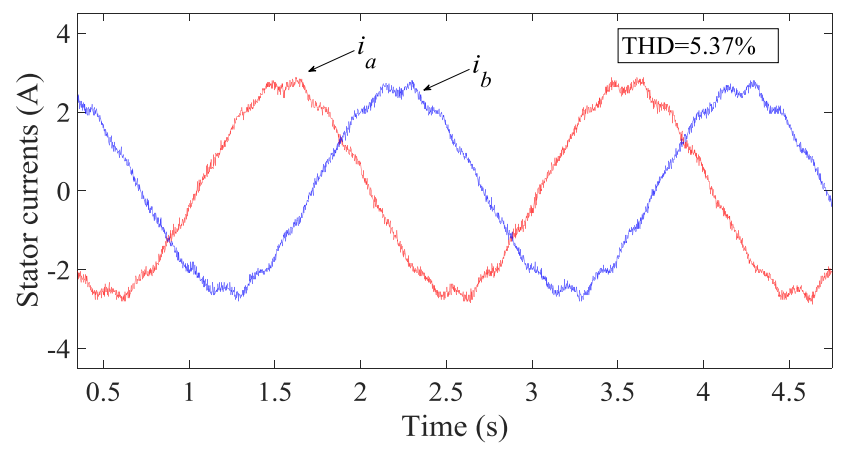

$a$

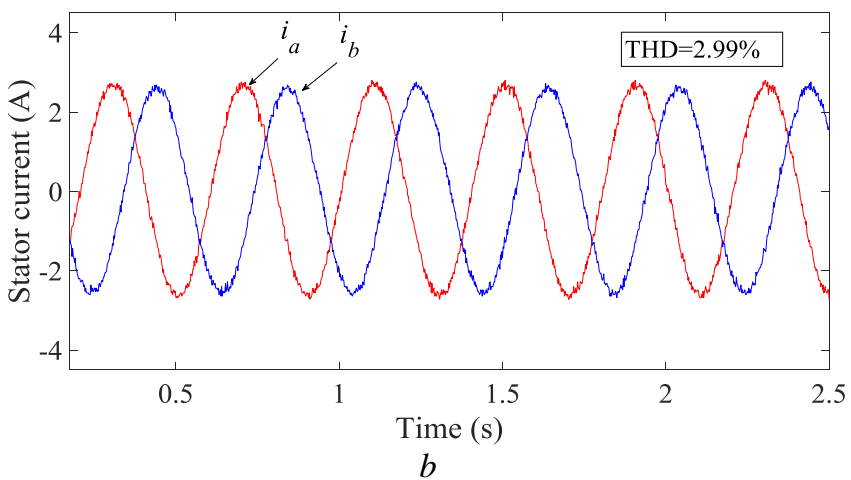

Fig. 7. Experimental results of $\mathrm{HB}-\mathrm{FOC}$ controlled $M C$ based PMSM drive (steady-state results 1): (a) PMSM stator currents when $\omega=10 \mathrm{rpm}$ and $T_{L}=1.5 \mathrm{~N} \cdot \mathrm{m}$, (b) $P M S M$ stator currents when $\omega=50 \mathrm{rpm}$ and $T_{L}=1.5 \mathrm{~N} \cdot \mathrm{m}$. 
In order to verify the feasibility and effectiveness of the proposed strategy, the experimental work was implemented in a scaled-down MC-based drive system. The experiment set up is shown in Fig. 6. The clamp circuit is not shown in the figure, however, it is used in the hardware to protect devices from overvoltage. The bidirectional switches (IGBTs) are arranged in the common collector configuration. As a result, only six independent driver power supplies are required for driving eighteen IGBTs. The control card was a TI TMS320F28377D series DSP board. Real-time control implementation was carried out in MATLAB/Simulink with C2000 hardware support packages. A serial communications interface (SCI) was used for the communication between the host and DSP card. An enhanced quadrature encoder pulse (eQEP) was used to obtain the rotor angular position, thus the motor speed. The motor encoder used had 2000 lines which is a high resolution encoder. Analog to digital conversion
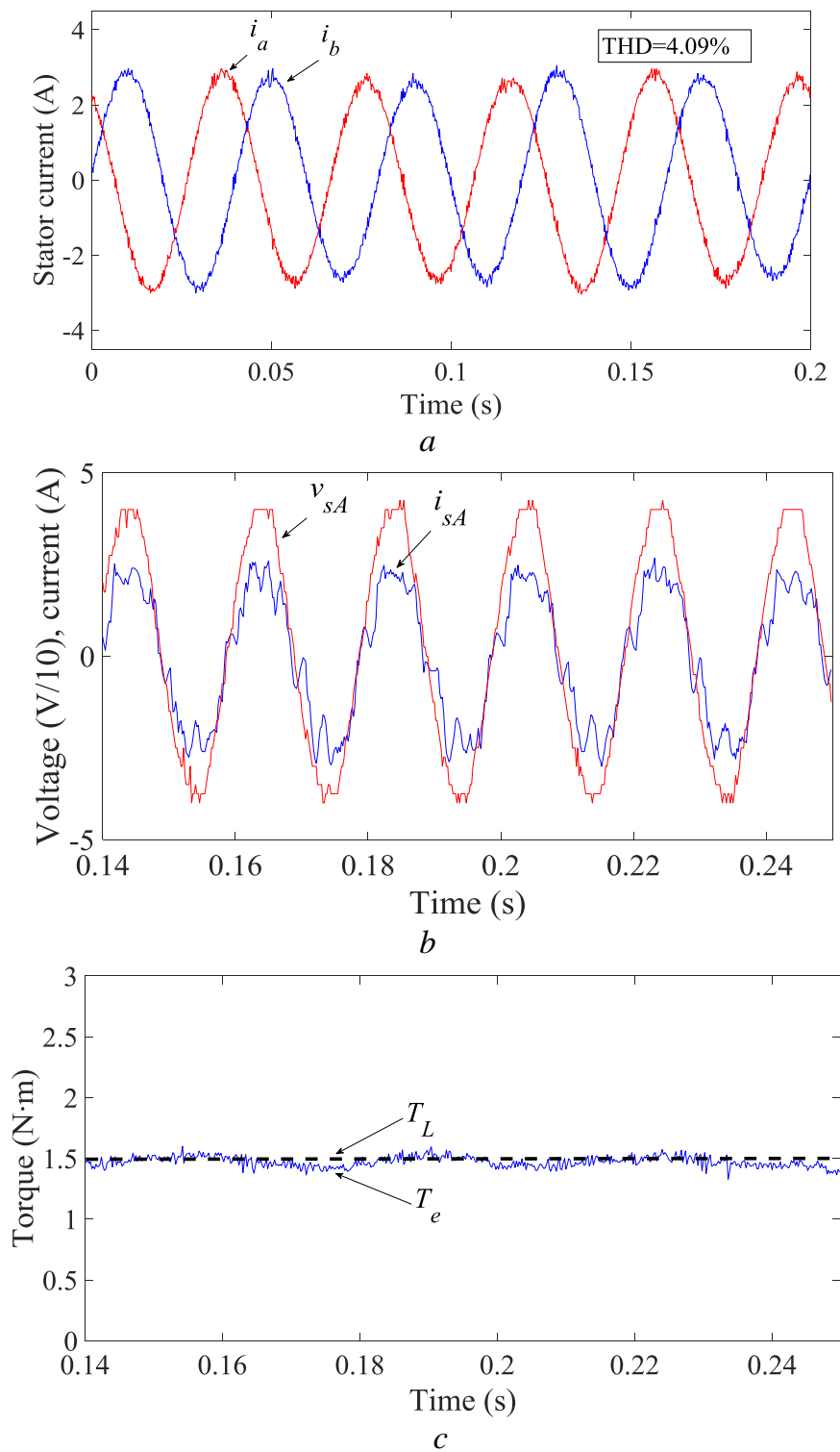

Fig. 8. Experimental results for HB-FOC controlled MC based PMSM drive (steady-state results 2): (a) PMSM stator currents when $\omega=500 \mathrm{rpm}$ and $T_{L}=1.5 \mathrm{~N} \cdot \mathrm{m}$, (b) MC input phase voltage and current when $\omega=300 \mathrm{rpm}$ and $T_{L}=1.5$ $N \cdot m,(c)$ PMSM torque performance when $\omega=300 \mathrm{rpm}$ and $T_{L}$ $=1.5 \mathrm{~N} \cdot \mathrm{m}$.
(ADC) and peripheral circuits were employed to process the signals from voltage and current sensors.

Parameters of the tested surface-mounted PMSM are tabulated in Table 2. Since the performances of the F-HB and S-HB based controllers are very similar and S-HB renders heavier computation burden, here only F-HB is tested on hardware to demonstrate the effectiveness of the controller for the MC-based drive. The code execution time was around $25 \mu \mathrm{s}$, which is a light computational burden. The sample time should be higher than the execution time so that the code has enough time to be executed during each sample interval.

In the experimental results, all THD values are shown for the stator current of phase $a$. The steady-state performances are presented in Figs. 7 and 8. Fig. 7 shows the steady-state results for the low speed operation (10 and 50 $\mathrm{rpm}$ ) with a load torque of $1.5 \mathrm{~N} \cdot \mathrm{m}$ applied. Sinusoidal stator currents were obtained with the proposed control strategy. The stator current THDs are relatively low, i.e., 5.37\% and $2.99 \%$ for speeds of 10 and $50 \mathrm{rpm}$ respectively. These results validate that the proposed controller is effective in regulating low-speed operation. Fig. 8 shows the steady-state regulation performance of the proposed controller for relatively higher speeds. Fig. 8(a) shows the steady-state stator currents for 500 rpm with a $1.5 \mathrm{~N} \cdot \mathrm{m}$ load applied. The THD for the stator current is $4.09 \%$. In Fig. 8(b) and (c) the rotor speed is 300 $\mathrm{rpm}$ and a load torque of $1.5 \mathrm{~N} \cdot \mathrm{m}$ is applied. The input current is usually not a control objective in the VSI based motor drive system; however, with the proposed approach, the MC input currents were regulated and the results are shown in Fig. 8(b).
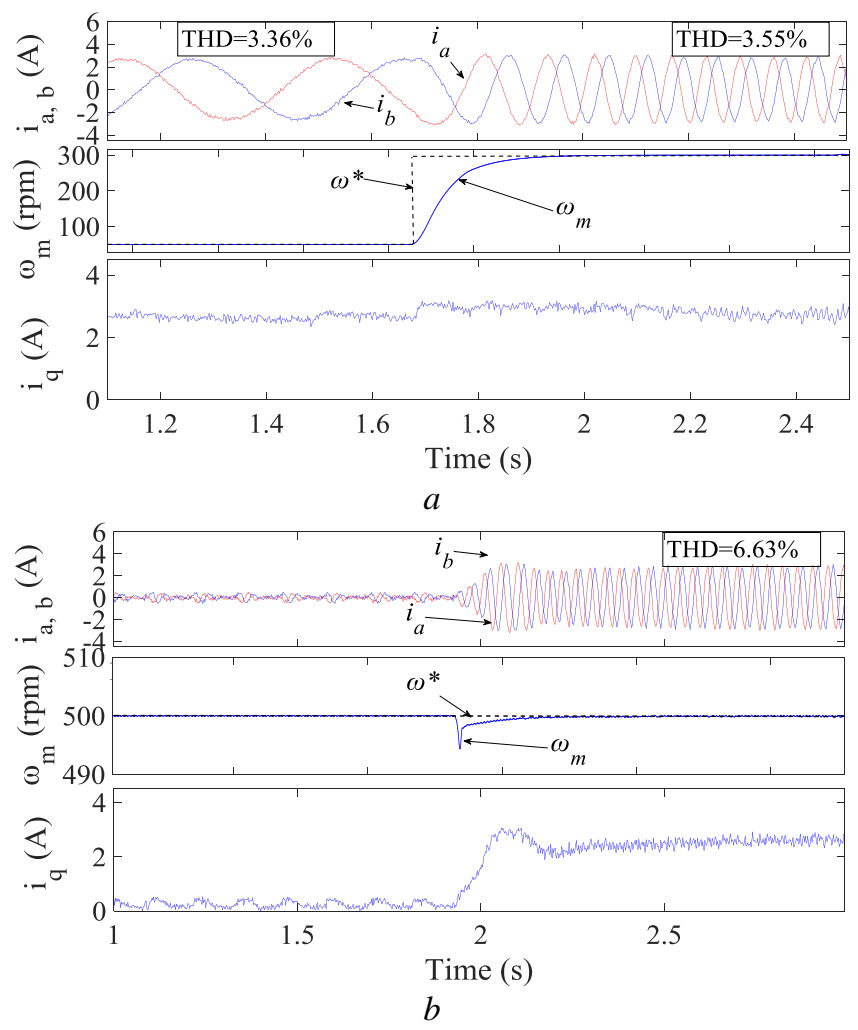

Fig. 9. Experimental results of HB-FOC controlled MC based PMSM drive (transient results 1): (a) PMSM stator currents, rotor speed and q-axis component current responses to command speed step change from 50 to $300 \mathrm{rpm}$ when $T_{L}=1.5 \mathrm{~N} \cdot \mathrm{m}$, (b) PMSM stator currents, rotor speed and q-axis current component to load torque step change from 0 to $1.5 \mathrm{~N} \cdot \mathrm{m}$ when $\omega=500 \mathrm{rpm}$. 
The input power factor is around one (unity power factor operation) in this case. The input current is distorted. This is because it is regulated by the inherent line-commutated modulation of the proposed hysteresis band current controller. The PMSM electromagnetic torque is shown in Fig. 8(c).

The experimental results of the transient behaviour are shown in Figs. 9 and 10. Fig. 9 shows the results when the output power is increased either by increasing the rotor speed or the applied load torque. Fig. 9(a) shows the PMSM stator currents, rotor speed and q-axis current responses to a speed change from 50 to $300 \mathrm{rpm}$ when a load $T_{L}=1.5 \mathrm{~N} \cdot \mathrm{m}$ is applied. Fig. 9(b) demonstrates the PMSM stator currents, rotor speed, and q-axis current responses to the step load change from 0 to $1.5 \mathrm{~N} \cdot \mathrm{m}$ when the rotor speed is maintained at $500 \mathrm{rpm}$. As seen from these figures, the proposed control strategy can track and maintain the target speed effectively. Fast dynamics are achieved, while with the overshoot appearing in the waveforms. By tuning the PI parameters, the dynamic performance and overshoot can be adjusted. Fig. 10 shows the test results when the output power is decreased by reducing the rotor speed. In Fig. 10(a), the PMSM stator currents and MC input current are shown for PMSM deceleration from 350 to $250 \mathrm{rpm}$ when the load torque is 1.5 $\mathrm{N} \cdot \mathrm{m}$. The rotor speed and q-axis current for this test are shown in Fig. 10(b). These results show good regulation performance of the proposed controller during deceleration.

From the above simulation and experimental results, the effectiveness of the MC based PMSM drive system under steady-state and transient tests is demonstrated. The THDs of the stator current under various tests are low, ranging from $2.99 \%$ to $6.63 \%$. The proposed control method is simple and

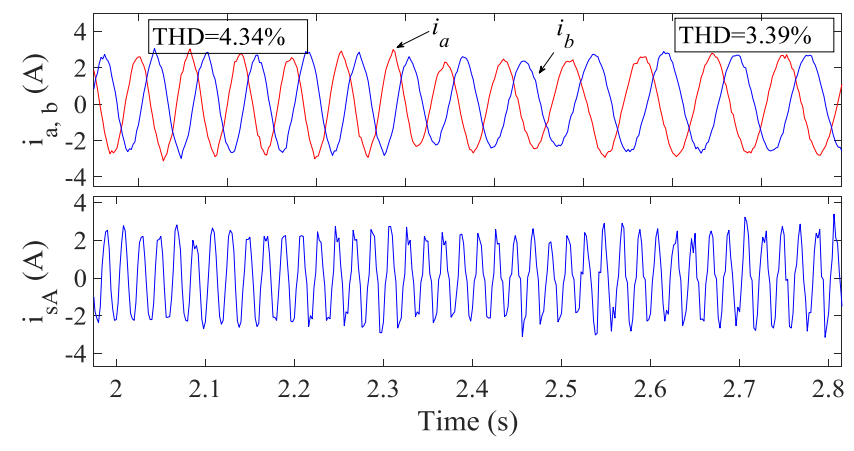

$a$

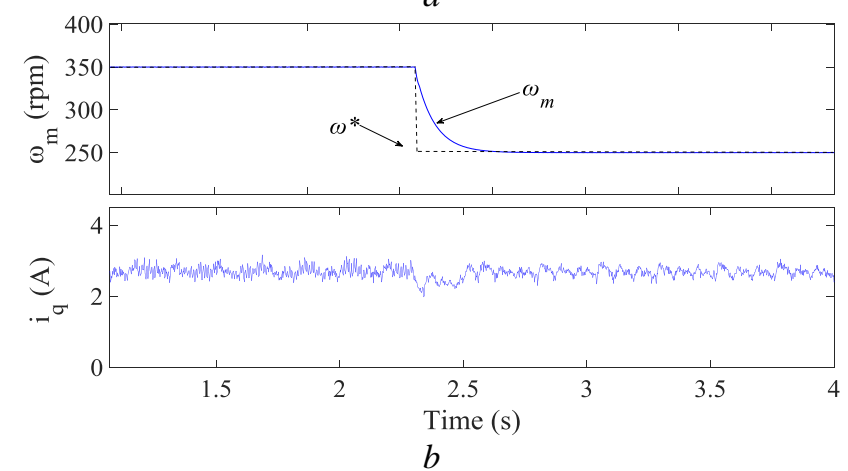

Fig. 10. Experimental results of HB-FOC controlled $M C$ based PMSM drive (transient results 2): (a) PMSM stator current and MC input current response, (b) PMSM rotor speed and q-axis current component response to command speed step change from 350 to $250 \mathrm{rpm}$ (deceleration) when $T_{L}=1.5 \mathrm{~N} \cdot \mathrm{m}$. practical for real-world applications such as many adjustable speed motor drives.

\section{Conclusions}

The hysteresis band controller based on FOC is popular in VSIs and motor drives based on VSIs; however, it has not been reported in the literature for a direct $3 \times 3 \mathrm{MC}$ or MC-based drive system. This paper introduces the $\mathrm{HB}$ current controller to the MC and MC based AC drive system. This method is simple and the computation burden is light. Both the fixed and sinusoidal band HB controllers that are developed involve inherent modulation of the input currents, and simulation results are evaluated comparatively. S-HB has better harmonic performance and higher average switching frequency. It is shown that S-HB has significantly superior performance over F-HB only at high sampling frequencies. The input current regulation is achieved through the linecommutated modulation. Better input currents regulation results can be achieved by integrating other methods, such as SVM, into the overall modulation. With the MC based drive, the braking chopper is not required. It is important to state that this scheme cannot only be applied to the PMSM but also to other machines such as induction motors. The proposed scheme is explicit, effective and suitable for practical applications. Experimental results demonstrate the effectiveness of the proposed controller and MC in driving PMSM.

\section{References}

[1] Rodriguez, J., Kennel, R. M., Espinoza, J. R., Trincado, M., Silva, C.A. and Rojas, C.A.: 'High-performance control strategies for electrical drives: An experimental assessment', IEEE Trans. Ind. Electron., 2012, 59, (2), pp. 812-820

[2] Raisemche, A., Boukhnifer, M., Larouci, C., and Diallo, D.:'Two active fault-tolerant control schemes of induction-motor drive in EV or HEV', IEEE Trans. Veh. Technol., 2014, 63, (1), pp. 19-29

[3] Guzinski, J., Abu-Rub, H.: 'Speed sensorless induction motor drive with predictive current controller', IEEE Trans. Ind. Electron., 2013, 60, (2), pp. 699-709

[4] Wu, F., Zhang, L., and Wu, Q.: 'Simple unipolar maximum switching frequency limited hysteresis current control for grid-connected inverter', IET Power Electronics, 2013, 7, (4), pp. 933-945.

[5] Peter, J., Marques, G. D., Ramchand, R.: 'Current error space vector based constant switching frequency hysteresis controller for VSI fed Induction Motor drives', 9th Int. Conf. Compatibility and Power Electron., Lisbon, Portugal, 2015, pp. 246-251

[6] Ramchand, R., Gopakumar, K., Patel, C., Sivakumar, K., Das, A. and Abu-Rub, H.: 'Online computation of hysteresis boundary for constant switching frequency current-error space-vector-based hysteresis controller for VSI-fed IM drives', IEEE Trans. Power Electron., 2012, 27, (3), pp. 1521-1529

[7] Wu, F., Feng, F., Luo, L., Duan, J. and Sun, L.: 'Sampling period online adjusting-based hysteresis current control 
without band with constant switching frequency', IEEE Trans. Ind. Electron., 2015, 62, (1), pp. 270-277

[8] Wang, L., Lam C. S., Wong M. C., Dai, N.Y., Lao, K.W. and Wong, C.K.: 'Non-linear adaptive hysteresis band pulse-width modulation control for hybrid active power filters to reduce switching loss', IET Power Electronics, 2015, 8, (11), pp. 2156-2167

[9] Tripathi, A., Sen, P. C.: 'Comparative analysis of fixed and sinusoidal band hysteresis current controllers for voltage source inverters', IEEE Trans. Ind. Electron., 1992, 39, (1), pp. 63-73

[10]Zhang, J., Li, L., Dorrell, D. G.: 'Hysteresis Band Current Controller based Field-Oriented Control for an Induction Motor driven by a Direct Matrix Converter, 43rd Ann. Conf. Ind. Electron. Society, Beijing, China, October 2017

[11]Li, X., Su, M., Sun, Y., Dan, H. and Xiong, W.: 'Modulation strategies based on mathematical construction method for matrix converter under unbalanced input voltages', IET Power Electronics, 2013, 6, (3), pp.434-445

[12]Dabour, S. M. and Rashad, E. M.: 'Analysis and implementation of space-vector-modulated three-phase matrix converter', IET Power Electronics, 2012, 5, (8), pp.1374-1378

[13]Wheeler, P. W., Rodriguez, J., Clare, J. C., Empringham, L. and Weinstein, A.: 'Matrix converters: a technology review', IEEE Trans. Ind. Electron., 2002, 49, (2), pp. 276-288

[14]Pinto, S. F., Mendes, P. V., Fernando Silva J.: 'Modular matrix converter based solid state transformer for smart grids', Electric Power Syst. Research, 2016, 136, pp. 189200

[15]Zhang, J., Li, L., Malekjamshidi, Z., Dorrell, D. G.: 'Predictive Voltage Control of Direct Matrix Converter with Reduced Number of Sensors for the Renewable Energy and Microgrid Applications', IEEE Energy Conversion Congress and Exposition, Cincinnati, U.S., October 2017, pp. 3309-3315

[16]Zhang, J., Dorrell, D. G. and Li, L.: 'Applications of the Direct Space Vector Modulation Controlled Matrix Converter as the Unified Power Flow Controller', 8th Int. Conf. Power Electronics, Machines and Drives, Glasgow, UK, April 2016, pp. 1-6

[17]Bak, Y., Lee, E., and Le, K. B.: 'Indirect matrix converter for hybrid electric vehicle application with three-phase and single-phase outputs', Energies, 2015, 8, (5), pp. 3849-3866

[18] Casadei, D., Serra, G., Tani, A.: 'The use of matrix converters in direct torque control of induction machines', IEEE Trans. Ind. Electron., 2001, 48, (6), pp. 1057-1064

[19]Xia, C., Zhao, J., Yan, Y. and Shi, T.: 'A novel direct torque control of matrix converter-fed PMSM drives using duty cycle control for torque ripple reduction', IEEE Trans. Ind. Electron.,2014, 61, (6), pp. 2700-2713

[20]Vargas, R., Ammann, U., Hudoffsky, B., Rodriguez, J. and Wheeler, P.: 'Predictive torque control of an induction machine fed by a matrix converter with reactive input power control', IEEE Trans. Power Electron., 2010, 25, (6), pp. 1426-1438

[21] Yan, Y., Zhao, J., Xia, C. and Shi, T.: 'Direct torque control of matrix converter-fed permanent magnet synchronous motor drives based on master and slave vectors', IET Power Electronics, 2014, 8, (2), pp.288296

[22]Ortega, C., Arias, A., Caruana, C., Balcells, J. and Asher, G.M.: 'Improved waveform quality in the direct torque control of matrix-converter-fed PMSM drives', IEEE Trans. Ind. Electron., 2010, 57, (6), pp. 2101-2110

[23]Lee, K. B., Blaabjerg, F.: 'Sensorless DTC-SVM for induction motor driven by a matrix converter using a parameter estimation strategy', IEEE Trans. Ind. Electron., 2008, 55, (2), pp. 512-521

[24]Zhang, J., Li, L., Dorrell, D.: 'Direct Torque Control with a Modified Switching Table for a Direct Matrix Converter based AC Motor Drive System', 20th Int. Conf. Electrical Machines and Systems, Sydney, Australia, August 2017.

[25]Lee, K.-B., and Blaabjerg, F.: "An improved DTC-SVM method for sensorless matrix converter drives using an overmodulation strategy and a simple nonlinearity compensation." IEEE Trans. Ind. Electron., 2007, 54, (6), pp. 3155-3166

[26]Gupta, R., Ghosh, A., Joshi, A.: 'Multiband hysteresis modulation and switching characterization for slidingmode-controlled cascaded multilevel inverter', IEEE Trans. Ind. Electron., 2010, 57, (7), pp. 2344-2353

[27]Abu-Rub, H., Iqbal, A., Guzinski, J.: 'High performance control of AC drives with MATLAB/Simulink models', (John Wiley \& Sons, 2012) 